\title{
PENANAMAN NILAI-NILAI KARAKTER PADA SISWA SEKOLAH DASAR MELALUI CERITA RAMAYANA
}

\author{
Oleh: \\ Ni Wayan Sukiningsih \\ Mahasiswa Jurusan PGSDH Fakultas Dharma Acarya \\ Institut Hindu Dharma Negeri Denpasar \\ sukiningsih96@gmail.com
}

diterima 18 Maret 2019, direvisi 22 Maret 2019, diterbitkan 29 April 2019

\begin{abstract}
This paper aims to describe the character values of elementary school students through Ramayana stories. Character education in elementary school is an effort to build character of elementary school student. There is a shift in values regarding norms of decency, ethics and morality. Moral degradation can be regarded as an indicator of the weak understanding of religious values. In Hindu Literature, especially in Itihasa, in which there is a Ramayana story, this story is full of character values. In the classroom learning the teacher at least tucked the story with the goal of students can adopt the character of every character in the Ramayana story that can make students become comfortable in following the lessons and can implement in every aspect of life, and is expected to motivate and provide new paradigm in the effort shaping the character of the young generation.
\end{abstract}

Keywords: Character Education, elementary school students, Itihasa

\section{PENDAHULUAN}

Dewasa ini masyarakat dihadapkan pada situasi yang menuntut penyesuaian terhadap perubahan yang begitu cepat di hampir setiap lini kehidupan. Perubahan tersebut tidak hanya dalam gaya hidup melainkan pada tingkah laku dan karakter setiap masyarakat terutamanya anak-anak. Pendidikan sesungguhnya bertujuan untuk memanusiakan manusia. Ketika seorang anak manusia lahir ke dunia, ia dibekali dengan berbagai potensi yang harus diaktualisasikan. Proses aktualisasi potensi secara sengaja inilah yang merupakan proses pendidikan. Proses ini berlangsung sampai seorang anak mencapai kedewasaan. Kedewasaan diri dapat ditunjukkan juga dengan kepribadian yang matang yaitu kepribadian yang menunjukkan karakter diri sebagai manusia yang baik, manusia yang mengaktualisasikan nilai-nilai kebenaran dan kebaikan dalam hidupnya. Tujuan pendidikan nasional sebagaimana ermaktub di dalam peraturan perundang-undangan sejak dahulu sampai sekarang, diketahui bahwa rumusan tujuan manusia baik berjalan seiring dengan tujuan manusia cerdas (pintar).

Pendidikan erat kaitannya dengan nilai- nilai, bahkan pendidikan itu mengandung nilai objektif. Salah satu nilai yang penting dalam pendidikan adalah nilai moral. Masalah moral berhubungan dengan keutuhan karakter. Memiliki kebajikan tidak sama dengan telah tertanamnya perilaku eksklusif tertentu. Memiliki kebajikan tampak nyata dalam diri seseorang ketika ia mampu 
berhubungan dengan yang lain dalam segala bidang kehidupan. Moral dan kualitas sosial dalam perilaku manusia adalah identik satu sama lain. Jadi, dapat disimpulkan bahwa nilai moral tercermin dalam karakter manusia.

Pendidikan karakter adalah suatu upaya atau tindakan yang didalamnya terdapat unsur mendidik. Pendidikan karakter memiliki peran yang sangat penting untuk memperkokoh mental dan karakter generasi muda agar sejalan dengan tujuan pendidikan yakni membentuk karakter yang baik (Titib, 2003: 19). Untuk mewujudkan hal ini memang tidaklah mudah, namun dapat diupayakan dengan memanfaatkan media tertentu sebagai sarana untuk mentransmisi nilai-nilai pendidikan karakter. Seperti kita ketahui sekarang ini tingkah laku anak-anak sudah sangat menyimpang dikarenakan pengaruh teknologi dan lingkungan. Anak sekolah dasar sekarang ini banyak yang sudah menggangap dirinya seperti orang dewasa, mereka sudah mulai mengikuti gaya anak remaja yang sebenarnya belum pantas untuknya seperti kebut-kebutan dijalan, merokok, menggunakan makeup yang berlebihan. Kertajaya (dalam Wiguna, 2018) mengatakan Karakter dapat diartikan sebagai ciri khas yang dimiliki oleh suatu benda atau individu tersebut, serta merupakan "mesin" yang mendorong bagaimana seorang bertindak, bersikap, berucap dan merespon sesuatu.). Hal ini sangat penting menjadi PR besar bagi para guru dan orang tua untuk lebih ekstra dalam membimbing anak-anak dan memberikan pendidikan karakter yang tepat.

Agama idealnya sebagai alat untuk menuntun sikap dan prilaku umat manusia ke arah yang lebih baik dan selalu berlandaskan kebenaran. Keberhasilan pemahaman ajaran agama tercermin melalui tindakan manusia itu sendiri. Demikian pula halnya Agama Hindu yang senantiasa mengingatkan umatnya untuk selalu mengutamakan dharma dalam kehidupan. Ajaran Agama Hindu bersumber dari Catur Veda, dan dijabarkan ke dalam kitab-kitab Smrti serta susastra-susastra Hindu. Ramãyana sebagai kitab suci Veda ditulis oleh Bhãgawan Walmiki. Menurut tradisi, kejadian yang dilukiskan di dalam Ramãyana menggambarkan kehidupan pada zaman Tretayuga tetapi menurut kritikus Barat berpendapat bahwa Ramãyana sudah selesai ditulis sebelum tahun 500 S.M. Diduga ceritanya telah populer tahun 3100 S.M.

\begin{tabular}{lcrr}
\multicolumn{4}{c}{ Menurut Rampan (2014: 13) } \\
secara sederhana cerita rakyat \\
memiliki beberapa fungsi yang \\
pertama & sebagai pelipur lara,
\end{tabular} kemudian fungsi selanjutnya sebagai sarana pendidikan sehingga sebagian besar cerita rakyat berisi kisah-kisah didaktik yang memperlihatkan tokohtokoh teguh dengan pendirian, berbudi pekerti luhur, jujur, setia, beriman, memiliki sifat-sifat ksatria, arif bijaksana, tujuannya untuk memberi teladan yang baik agar diikuti dan ditiru oleh masyarakat pendukungnya. Fungsi lainnya adalah sebagai kritik sosial atau protes sosial yang biasanya muncul karena ketidakpuasan masyarakat atas situasi atau suasana tertentu yang ada pada jamannya. Disamping itu, fungsi cerita rakyat adalah sebagai sarana untuk menyatakan sesuatu yang sukar dikatakan secara langsung.. Kitab Purāna menyebutkan ada sepuluh awatara Visnu, satu diantaranya adalah Rāmā. Disekolah guru dapat memulai 
menanamkan nilai-nikai karakter siswanya dengan memceritakan kisah Rama yang sangat baik dan taat serta patuh kepada orang tuanya.

\section{METODE}

Metode yang dipergunakan dalam penelitian ini adalah metode kepustakaan, dilakukan dengan mengkaji literature yang berkaitan dengan pendidikan karakter, metode bercerita dan pendidikan dasar. Sumber tulisan berasal dari buku, jurnal serta artikel ilmiah online.

\section{PEMBAHASAN}

Degradasi moral merupakan ciri lemahnya pemahaman umat manusia akan ajaran agamanya. Belakangan ini fenomena yang terjadi di dunia pendidikan adalah adanya "siswa yang memukul gurunya hingga meninggal " yang sangat menyudutkan sekolah dan mempertanyakan mengenai pendidikan karakter di sekolah apakah sudah diterapkan oleh dewan guru atau tidak. Nah disinilah peran guru sekolah dasar yang mana sekolah dasar merupakan pendidikan paling utama untuk anak, di sekolah asar anak dapat mengenal lingkungan dan mendapat pengetahuan, peran guru sangat penting untuk menanamkan nilai karakter kepada siswanya melalui media-media yang dianggap paling relevan untuk menyampaikan nilai karakter tersebut kepada siswa. Media yang dapat digunakan oleh guru bisa berupa cerita dalam kesusastraan hindu yang sarat akan nilai karakter. Kesusastraan Hindu memiliki peran yang cukup penting dalam hal pendidikan karakter, hal ini dapat dipahami bahwa nilai yang terkandung di dalamnya tidak hanya menyangkut ajaran agama, melainkan juga dibangun oleh nilainilai etika, moralitas, pendidikan serta alur cerita maupun penggunaan bahasanya yang indah (Wiguna, 2018). Cerita yang paling tepat digunakan sebagai media untuk menanamkan nilai karakter pada siswa adalah cerita Ramayana.

Nilai

Dalam kamus besar Bahasa Indonesia disebutkan bahwa nilai adalah sifat-sifat yang penting bagi kemanusiaan. Menurut Koentjaraningrat nilai adalah ide-ide yang mengkonsepkan hal-hal yang paling bernilai di dalam kehidupan. Konsepsi-konsepsi serupa itu biasanya luas dan kabur. Justru karena kabur atau irasional biasanya berakar dalam emosional dari alam jiwa manusia.

Dari kutipan diatas dapat disimpulkan nilai merupakan sebuah kualitas yang tertanam dalam sifat emosional manusia.

\section{Karakter}

Menurut teks Hindu menjelaskan bahwa karakter adalah sesuatu yang MENJIWAI tindakan tindakan manusia di dalam kehidupan sehari-hari. Orang yang berkarakter adalah orang yang ekspresi hidupnya mengarah pada nilai-nilai kemanusiaan atau nilai-nilai spiritual, apa yang muncul, yang terekspresi di dalam pola berpikir, berbicara, maupun bertindak tergantung dari karakter. Dalam Pendidikan nasional di kenal adanya 18 jenis nilai karakter diantaranya: 1) Religius; 2) Jujur; 3) Toleransi; 4) Disiplin, 5) Kerja keras, 6) Kreatif; 7) Mandiri; 8) Demokratis; 9) Rasa ingin tahu; 10) Semangat kebangsaan; 11) Cinta tanah air; 12) Menghargai prestasi; 13) Bersahabat; 14) Cinta damai; 15) Gemar membaca; 16) Peduli lingkungan; 17) Peduli social dan 18) Tanggung jawab. Kedelapambelas nilai karakter ini 
harus diterapkan disekolah sebagai langkah awal untuk menjadikan Negara ini sebagai Negara yang berkarakter dan bermoral.

\section{Ramayana}

Secara etimologi Itihasa terbagi atas tiga kata yaitu "Iti"-"Ha" dan "Asa". "Iti" dan "Ha" adalah kata tambahan yang "indiclinable" di dalam bahasa Inggris. Dan "Asa" adalah kata kerja "Verb". Jadi arti Itihasa adalah "ini sudah terjadi begitu". Secara garis besar, Itihasa dibagi menjadi dua bagian yaitu Ramayana dan Mahabharata. Kedua Viracarita atau epos besar ini disebut juga Arsakavya. Kata Arsakavya berarti syair yang sangat indah. Secara etimologi Ramayana berasal dari bahasa Sansekerta dari kata "Rama" dan "Ayana" yang artinya perjalanan Rama. Kitab Ramayana menceritakan tentang kisah perjalanan Rama. Penulis dari Ramaya adalah Maharsi Valmiki. Ramayana terdiri dari 7 Kanda/Jilid dan 24.253 sloka). Isi dari kitab ini menggambarkan kehidupan di jaman Treta Yuga, tetapi menurut sarjana Barat Ramayana selesai ditulis sebelum tahun 500 SM, di duga ceritranya sudah populer tahun 3100 SM. Ramayana juga dikenal dengan nama lain Caturvinsati-sahasriSamhita. Buku Ramayana karya Valmiki menurut edisi Ramayana oleh Sri Ramakosa Mandala, SadaSivapith, Poona, India, terdiri dari 7 kanda, 659 sarga dan 23.864 sloka sebagai berikut: 1) Bala Kanda terdiri dari 77 sarga 2226 Sloka; 2) Ayodhya Kanda terdiri dari 119 Sarga 4185 Sloka; 3) Aranya Kanda terdiri dari 75 Sarga 2441 Sloka; 4) Kiskindha Kanda terdiri dari 67 Sarga 2453 Sloka; 5) Sundara Kandaterdiri dari 69 Sarga 2807 Sloka; 6) Yuddha Kanda terdiri dari 128 Sarga 5675
Sloka dan 7) Uttara Kanda terdiri dari 111 Sarga 3373 Sloka.

Selain diatas terdapat Praksipta (tambahan) 14 Sargah dan 664 Sloga. Jadi jumlah seluruhnya yakni 659 Sarga 23.864 Sloka. Umunya terdapat 3 edisi Ramayana yang sangat terkeal di India yakni Edisi India Timur, Selatan dan Utara. Ketiga edisi diatas jumlah slokanya berbeda-beda Halukta (dalam

https://hindualukta.blogspot.com/2015 /01/pengertian-dan-ruang-lingkup-

itihasa.html ). Untuk penanaman nilai karakter disekolah guru dapat menceritakan kisah Ramayana yang merupakan cerita hindu yang sarat akan nilai karakter. Adapu cerita Ramayana tersebut adalah:

\section{Membangun Nilai-nilai Karakter Pada Siswa Sekolah Dasar Melalui Cerita Ramayana}

Menurut Gunarsa

menyatakan bahwa Anak sekolah dasar adalah anak yang berusia 6-12 tahun, memiliki fisik lebih kuat mempunyai sifat individual serta aktif dan tidak bergantung dengan orang tua. Dalam hal belajar, anak sekolah dasar memiliki karakteristik senang bermain, bergerak, bekerja dalam kelompok, dan senang merasakan atau melakukan sesuatu secara langsung. Berdasarkan karakteristik anak sekolah dasar tersebut, maka dibutuhkan langkah-langkah yang tepat dalam mendidik siswa untuk membentuk karakter siswa sekolah dasar. Adapun langkah-langkah yang dapat dilakukan untuk membentuk karakter siswa sekolah dasar antara lain sebagai berikut:

1. Menentukan karakter Penentuan karakter dilakukan berdasarkan tujuan karakter yang diharapkan dalam artian setelah mengikuti seluruh 
proses pembelajaran, maka karakter yang terbentuk merupakan karakter yang yang sudah ditentukan. penentuan karakter untuk siswa sekolah dasar hendaknya disesuaikan dengan karakteristik siswa sekolah dasar, misalnya karakter disiplin dan tanggung jawab. Karakter tersebut dikira tepat karena karakteristik anak sekolah dasar adalah senang bermain, bergerak, bekerja dalam kelompok.

2. Melaksanakan penanaman karakter

Pelaksanaan penanaman karakter dilakukan melalui pembelajaran dengan cara mengintegrasikan karakter yang sudah ditentukan kedalam pembelajaran. adapun pengintegrasian karakter kedalam pembelajaran dapat dilakukan dengan cara, sebagai berikut:

a. Menentukan karakter menyelaraskan antara SK, KD dan Indikator yang didalamnya terkandung karakter yang ditananamkan.

b. Mengembangkan karakter yang sesuai dalam SK dan $\mathrm{KD}$.

c. Mencantumkan penanaman karakter dalam silabus dan RPP

d. Menyelipkan cerita-cerita yang sarat akan nilai karakter pada setiap pembelajaran.

Dalam cerita Ramayana tersebut banyak sekali nilai karakter yang dapat kita jelaskan kepada peserta didik. Dalam setiap pertemuan selalu selipkan ceria yng sarat akan nilai khalnya cerita Ramayana. Nilai karaker yang dapat kita jelaskan kepada perserta didik melalui cerita Ramayana ini diantaranya : Nilai Karakter disiplin, patuh dan setia, mandiri, tanggung jawab, kerja keras, cinta tanah air, dan cinta damai. Nilai karakter disiplin dan tanggung jawab dapat kita sampaikan pada saat Rama dan Laksamana mendapat tugas dari maha Rsi untuk menjaga pertapaannya dari serang para raksasa, nilai karakter kerja keras, patuh dan setia dan cinta tanah air serta mandiri dapat disampaikan melalui cerita saat pembuangan Rama ke hutan selama 14 tahun, nilai karakte cinta damai dapat kita lihat dari sikap Bharata yang tidak gila tahta walapun tahta kerajaan ayodhya berada di tangannya, namun dia tetap mempercayai Rama yang dapat memegang tahta dan pemerinatahan kerajaan ayodhya dengan baik. Dengan diselipkannya cerita hindu setiap kali pertemuan dikelas guru dapat membangun nilai karakter sedikit demi sedikit kepada siswa. Menurut Wiguna (2018) Terkait pendidikan karakter dalam sebuah karya sastra (termasuk satua sebagai tradisi sastra lisan) maka unsur tokohtokoh dan pesanlah yang dianggap paling menentukan. Artinya para tokoh menyampaikan pesan, amanat, nasihat yang disampaikan melalui penggunaan bahasa yang indah dan estetis. Karya sastra menyajikan berbagai masalah dalam kaitannya pendidikan moral, budi pekerti dan tata susila serta nasihat-nasihat lainnya. Dengan kata lain cerita-cerita hindu seperti halnya Ramayana sangat cocok diadikan media oleh gru untuk membangun nilai karakter siswa sekolah dasar, karena dalam tingkat pendidikan dasar siswa masih senang jika diajak/diberikan cerita dalam setiap pembelajaran dan cerita Ramayana ini sarat akan nilai karaker 
ADI WIDYA: Jurnal Pendidikan Dasar

Volume. 4, Nomor 1 April 2019

ISSN: 2527-5445

: http://ejournal.ihdn.ac.id/index.php/AW

terutamanya nilai karakter tanggung jawab. Jika pembangunan nilai karakter pada siswa dilakukan sejak jenjang sekolah dasar maka anak-anak generasi penerus bangsa akan memiliki karakter yang baik dan selalu mencintai negaranya.

\section{SIMPULAN}

Kesusastraan Hindu memiliki peran yang cukup penting dalam hal pendidikan karakter. Hal ini dapat dipahami bahwa nilai yang terkandung di dalamnya tidak hanya menyangkut ajaran agama, melainkan juga dibangun oleh nilai-nilai etika, moralitas dan pendidikan. Penanaman nilai karakter pada siswa sekolah dasar menjadi kunci utama terbentukan generasi muda yang memiliki intelegent tinggi dan berkarakter serta siap menerima tantangan era masa kini yang seba canggih dan instan. Sehingga guru dapat dijadikan suri tauladan bagi siswanya. Selain itu, guru harus menanamkan karakter dengan cara menyelipkan cerita kesusastraan hindu yang memiliki nilai karakter dalam setiap pembelajaran agar siswa mendapatkan pendidikan karakter setiap hari disekolah. dengan adanya hal tersebut. maka penanaman nilai karakter pada siswa sekolah dasar dapat tercapai dengan baik serta dengan penanaman nilai karakter di tingkat sekolah dasar diharapkan mampu mengatasi masalah degradasi moral pada anak yang kita hadapi saat ini, peran guru dan orang tua menjadi kunci utama keberhasilan penanaman nilai karakter pada anak sekolah dasar.

\section{DAFTAR PUSTAKA}

Sanjaya, Prof. Dr. H Wina. 2006. Strategi Pembelajaran. Bandung: Kencana

Wiguna, I. M. A. (2018, January). Mengurai Nilai-Nilai Moral
Dalam Satua Sebagai Media Pendidikan Karakter Di Era Global. In Prosiding Seminar Nasional Kearifan Lokal Indonesia Untuk Pembangunan Karakter Universal 2015 (pp. 232-241).

Undang-Undang Nomor 20 Tahun 2003, Tentang Sistem

Pendidikan Nasional. Jakarta:

Depdiknas

Titi, I Made. 2004. Purana. Surabaya : Paramita

Lal, P, 2015. Ramayana. Terjemahan Sang Ayu Putu Reny. Denpasar : Media Hindu

Wiguna, I. M. A. (2018). Karakter Anak Suputra dalam Itihasa dan Puraana (Sebuah Kontemplasi).

Gunarsa, S.D., \& Gunarsa, Y.S.D (2006). Psikologi Perkembangan Anak dan Remaja. Jakarta: PT BPK Gunung Mulia.

Daryanto, dan Suryatri Darmiatun. $2013 . \quad$ Impelementasi

Pendidikan Karakter di Sekolah. Yogyakarta: Gava Media

Aluka.hindu, 2015. https://hindualukta.blogspot.co $\mathrm{m} / 2015 / 01 /$ pengertian-danruang-lingkup-itihasa.html (akses pada tanggal 12 juni 2018, pukul 16.00 wita)

PF, K. A. P. D. 2017. The Empowerment Of Role Of The Family In Developing Character Of Environmental Awareness In Elementary School-Age

Children. Vidyottama

Sanatana: International Journal of Hindu Science and Religious Studies, 1(1), 77-83. 